\title{
Long-lasting memory of cellular immunity in a chronic myeloid leukemia patient maintains molecular response 5 after cessation of dasatinib
}

\author{
TATSURO JO ${ }^{1}$, KAZUHIRO NOGUCHI ${ }^{2}$, SHIZUKA HAYASHI ${ }^{2}$, SADAHARU IRIE $^{3}$, RISA HAYASE ${ }^{2}$, \\ HARUNA SHIOYA $^{2}$, YOUHEI KANEKO ${ }^{2}$, KENSUKE HORIO ${ }^{1}$ and JUN TAGUCHI $^{1}$ \\ Departments of ${ }^{1}$ Hematology, ${ }^{2}$ Clinical Laboratory and ${ }^{3}$ Pharmacy, \\ Japanese Red Cross Nagasaki Genbaku Hospital, Nagasaki 852-8511, Japan
}

Received September 7, 2017; Accepted December 14, 2017

DOI: $10.3892 / \mathrm{ol} .2017 .7720$

\begin{abstract}
Tyrosine kinase inhibitors (TKIs), including imatinib, dasatinib and nilotinib are primarily used in the initial treatment of chronic phase (CP)-chronic myeloid leukemia (CML), as CMLs harbor the BCR-ABL fusion product. An increased number of lymphocytes and large granular lymphocytes (LGLs) have been observed in patients treated with dasatinib, but not other TKIs. The LGLs have been reported to be primarily natural killer (NK) cells and cytotoxic T lymphocytes (CTLs). In the present study, a CP-CML patient who has maintained molecular response 5 for $>2.4$ years after stopping dasatinib was reported. Memory and effector CTLs and NK cells, were observed after 2.4 years of treatment-free remission, despite the fact that lymphocyte counts are not elevated in the patient. These results suggest that dasatinib may induce cellular immunity, including NK cells and CTLs and this cellular immunity may be maintained for a long period following cessation of dasatinib. The results suggest that this cellular immunity may provide a long-term cure without the need for continued TKI treatment.
\end{abstract}

\section{Introduction}

Chronic myeloid leukemia (CML) is caused by a reciprocal translocation in a hematopoietic stem cell between chromosomes 9 and 22, resulting in the bcr-abll fusion gene. The $b c r-a b l l$ fusion gene encodes a constitutively active tyrosine kinase. Currently, the tyrosine kinase inhibitors

Correspondence to: Dr Tatsuro Jo, Department of Hematology, Japanese Red Cross Nagasaki Genbaku Hospital, 3-15 Mori-machi, Nagasaki 852-8511, Japan

E-mail: firetj@nagasaki-med.jrc.or.jp

Key words: chronic myeloid leukemia, dasatinib, cytotoxic $\mathrm{T}$ lymphocyte, natural killer cell, $\mathrm{T}$ cell receptor $\mathrm{V} \beta$ gene repertoire, tyrosine kinase inhibitor
(TKIs) imatinib, dasatinib, and nilotinib are commonly used as the first line treatment for chronic phase (CP)-CML treatment (1-3). Each TKI can affect multiple kinases with different activities (4). These TKIs induce a high rate of deep molecular response, and approximately half of $\mathrm{CP}-\mathrm{CML}$ patients who cease TKI therapy can achieve treatment-free remission (TFR) (5-7). The lack of relapse in such patients may be brought about by immunological control of CML. The effectiveness of allogeneic donor lymphocyte infusion in relapsed CML patients after allogeneic hematopoietic stem cell transplantation suggests that lymphocytes can produce an anti-CML effect (8). An increased number of lymphocytes has been found in patients treated with dasatinib, and these lymphocytes were reported to be natural killer (NK) cells and cytotoxic T lymphocytes (CTLs) $(9,10)$. However, no detailed analysis on cellular immunity in CP-CML patients who cease TKI therapy has been performed. Here, we report a case of long-lasting memory of cellular immunity against CML.

\section{Materials and methods}

bcr-abll expression analyses. $m R N A$ extracted from bone marrow aspirates or peripheral blood samples was subjected to $b c r$-abll expression analyses. Quantitative analyses of major bcr-abll $m R N A$ were performed using $m R N A$ extracted from bone marrow aspirates or peripheral blood samples until June 2015, and the International Scale (IS) method of major bcr-abll mRNA analyses using peripheral blood samples has been applied since July 2015 (11). All analyses were performed by the SRL Corporation (Tokyo, Japan). We defined molecular response (MR) 3 as $\leq 0.1 \%$, MR4 as $\leq 0.01 \%$, and MR5 as $\leq 0.001 \%$ of major bcr-abll expression, respectively.

Cellular immunity analyses. Cellular immunity analyses were conducted using flow cytometry. Antibodies for assays of NK cells and CTLs were purchased from DACO Japan (Tokyo, Japan). IOTest Beta Mark T cell receptor (TCR) V $\beta$ ( Vb) repertoire kit (Beckman Coulter, Tokyo, Japan) was used for $T C R V b$ gene repertoire assays in $\mathrm{CD}^{+} \mathrm{T}$ cells. We performed flow cytometric analyses according to the manufacturers' instructions. 
Informed consent. Informed consent was obtained from the patient's son in Case 1, because the patient's consent could not be obtained due to dementia. Informed consent was obtained from the patients described in Cases 2 and 3.

\section{Case reports}

Case 1. A 75-year-old woman was diagnosed with CP-CML, and $400 \mathrm{mg} /$ day of imatinib, the first generation TKI, was started in January 2008. The results of gene expression analyses using $m R N A$ extracted from bone marrow aspirates in April 2009 and February 2011 revealed absence of $b c r-a b l l$, indicating MR5. Fifty milligrams of dasatinib, a second generation TKI, was administered instead of imatinib starting in May 2011 due to cramping in the calf that was thought to be an adverse effect of imatinib. Absence of $b c r$-abll was reconfirmed using $m R N A$ extracted from bone marrow aspirates in February 2012 and April 2013. She suffered from subdural hematoma due to a fall in January 2015, and dasatinib was stopped in March 2015. Absence of bcr-abll was reconfirmed using $m R N A$ extracted from peripheral blood in July 2017, more than 2.4 years after stopping dasatinib. Interestingly, elevation of lymphocyte count was observed only when the patient was receiving dasatinib (Fig. 1). Cellular immunity, represented by the NK cell, CTL, and regulatory T (Treg) cell populations, was investigated in July and August 2017. The percentage of $\mathrm{NK}$ cells, defined as $\mathrm{CD} 3{ }^{-} \mathrm{CD} 16^{+} \mathrm{CD}^{2} 6^{+}$, was $54.5 \%$. The percentages of effector memory CTLs, defined as $\mathrm{CD}^{+}{ }^{+} \mathrm{CD} 27^{+} \mathrm{CD} 57^{-}$, and terminal effector CTLs, defined as $\mathrm{CD} 8^{+} \mathrm{CD} 27^{-} \mathrm{CD} 57^{+}$, were 14.3 and $24.2 \%$, respectively (Table I). A TCR $V b$ gene repertoire assay showed that $V b 13.1$ was the most common gene variant in both effector and memory CD8 ${ }^{+} \mathrm{T}$ cells (Fig. 2). The rate of $\mathrm{Vbl3.1}$ in memory $\mathrm{CD}^{+} \mathrm{T}$ cells was extremely high $(65.1 \%)$. The percentages of effector and naïve Treg were 1.1 and $0.9 \%$, respectively, but we could not evaluate the changes in these populations because Tregs were not measured during TKI treatment.

Case-2 (control patient 1). A 72-year-old woman was diagnosed with CP-CML, and $600 \mathrm{mg} /$ day of imatinib was started in June 2004. Three months later, imatinib was stopped due to skin rash. Three hundred $\mathrm{mg}$ /day of imatinib was started again due to disease progression in July 2008 with no further evidence of skin rash. The dose of imatinib was reduced gradually to $100 \mathrm{mg} /$ day according to the patient's will. Absence of $b c r-a b l l m R N A$ was confirmed through December 2015. However, the molecular response level decreased from MR5 to MR3 (March 2016) and MR4 (September 2017). The patient's clinical course beginning in July 2008 is illustrated in Fig. 1B.

Case 3 (control patient 2). A 50-year-old man was diagnosed with CP-CML, and $600 \mathrm{mg} /$ day of nilotinib, a second generation TKI, was started in August 2011. Three weeks later, the dose of nilotinib was reduced to $400 \mathrm{mg}$ /day due to slight leukocytopenia and the dose was maintained until August 2016. Nilotinib was changed to $300 \mathrm{mg} /$ day of bosutinib, a second generation TKI, due to nilotinib-induced skin rash in August 2016. However, bosutinib was stopped due to bosutinib-induced diarrhea. After that, no TKIs have been

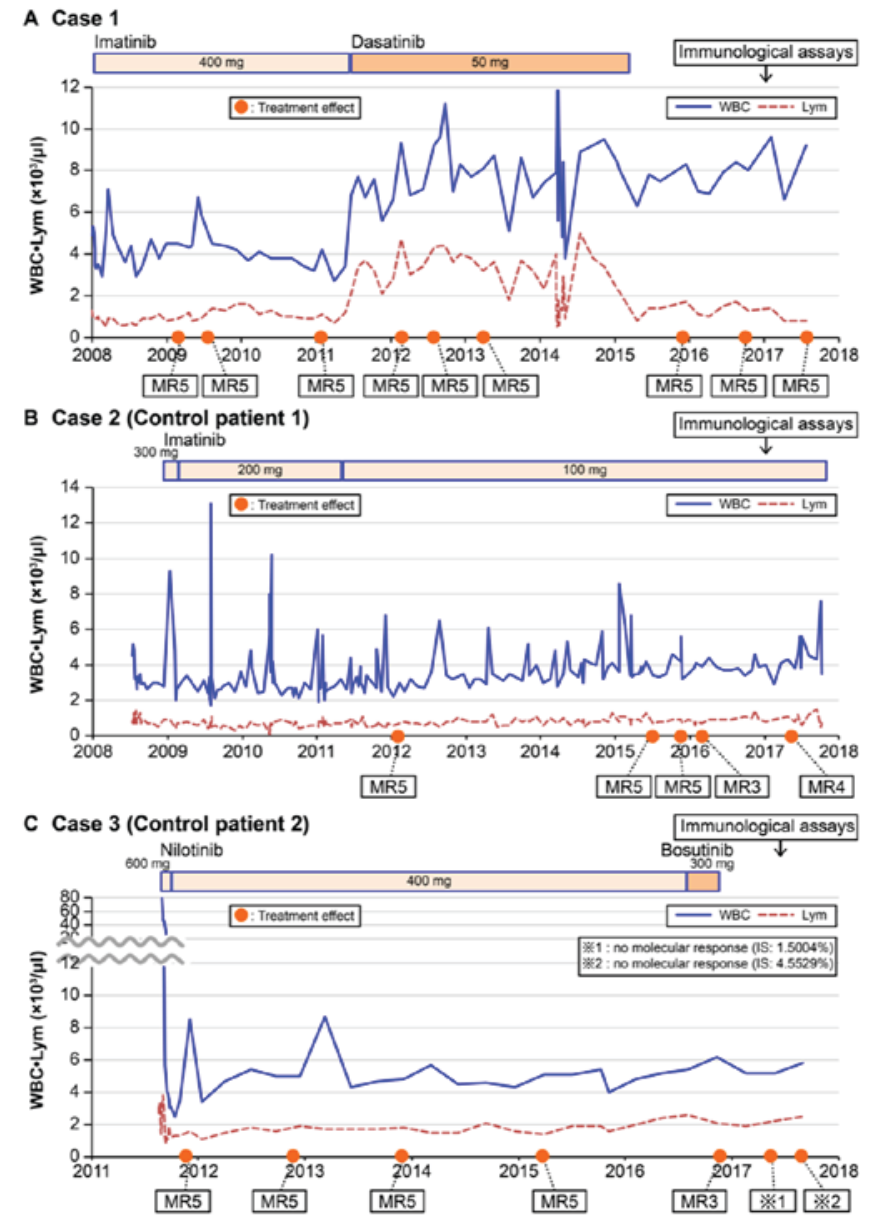

Figure 1. Clinical courses of (A) Case 1, (B) Case 2 (control patient 1), and (C) Case 3 (control patient 2). Blue lines indicate white blood cells (WBC) and dotted brown lines indicate lymphocytes (Lym). Treatment effect was examined by $b c r$-abll expression analysis using $m R N A$ extracted from bone marrow aspirates (Case 1, through June 2015) or peripheral blood samples (Case 1 after June 2015, Cases 2-3). Quantitative analyses of major bcr-abl1 $m R N A$ were performed through June 2015, and the International Scale (IS) method of major bcr-abl1 $m R N A$ analyses using peripheral blood samples was applied in July 2015. Control patient 2 (panel C; Case 3) has had no molecular response since 2017. Major bcr-abl1 mRNA expression levels in March and September 2017 were 1.5004 and $4.5529 \%$ by the IS method, respectively. MR, molecular response.

administered, according to the patient's will. Although absence of bcr-abll mRNA was confirmed through March 2015, the molecular response levels decreased from MR5 to MR3 (November 2016), and later, the patient had no molecular response (May and September 2017) (Fig. 1C).

\section{Discussion}

TKIs such as imatinib, dasatinib, and nilotinib have made a drastic impact on survival in patients with CP-CML (1-3). These patients now have life expectancies comparable to patients with lifestyle-related diseases such as hypertension and diabetes mellitus (12). However, TKIs cannot completely eliminate CML stem cells, and patients must continue treatment, which can be expensive. Some previous reports regarding cessation of TKIs showed that approximately half of patients could safely stop treatment under stringent treatment conditions (5-7); however, the parameters for safely 
Table I. Percentage of NK cells, effector memory CTLs and terminal effector CTLs in the patient and controls.

\begin{tabular}{lccc}
\hline Cell type & Case 1 & Case 2 (control patient 1) & Case 3 (control patient 2) \\
\hline NK cells (\%) & 54.5 & 24.1 & 16.6 \\
Effector memory CTLs (\%) & 14.3 & 6.4 & 21.8 \\
Terminal effector CTLs (\%) & 24.2 & 11.6 & 7.4 \\
\hline
\end{tabular}

NK cells were defined as CD16/CD56 positive, CD3 negative cells. Effector memory CTLs were defined as CD8/CD27 positive, CD57 negative cells. Terminal effector CTLs were defined as CD8/CD57 positive, CD27 negative cells. NK, natural killer; CTL, cytotoxic T lymphocyte.

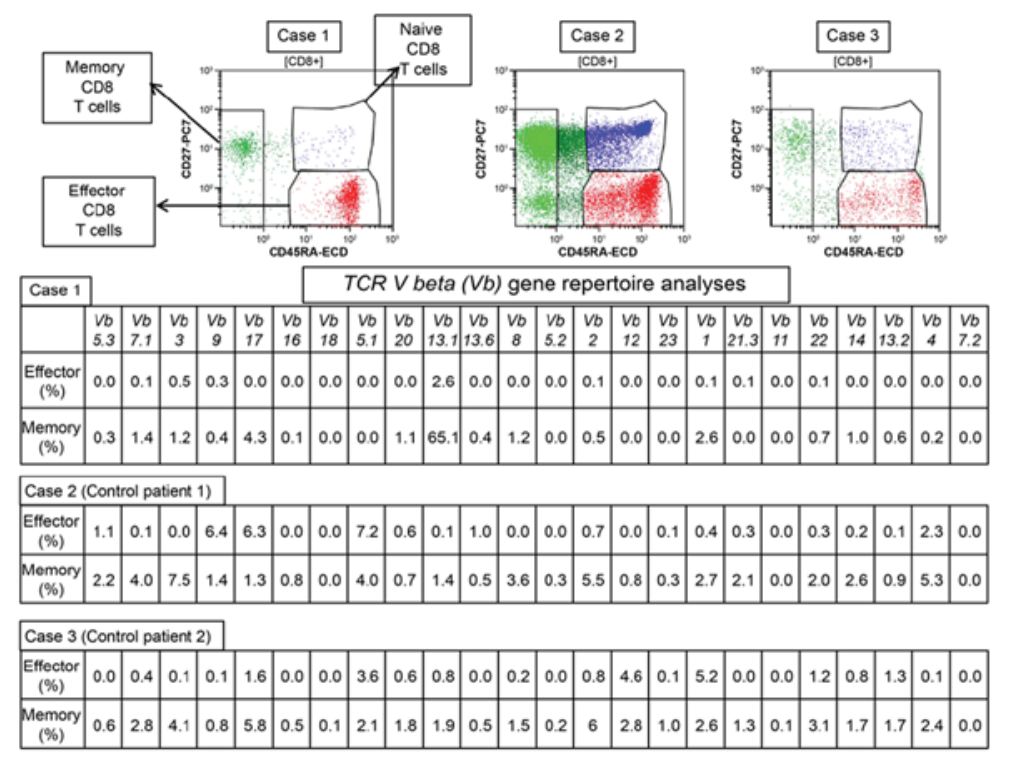

Figure 2. Analyses of the $\mathrm{T}$ cell receptor $(\mathrm{TCR}) \mathrm{V} \beta(\mathrm{Vb})$ gene usage of $\mathrm{CD} 8^{+} \mathrm{T}$ cells. Memory $\mathrm{CD} 8^{+} \mathrm{T}$ cells were defined as the $\mathrm{CD} 8^{+} \mathrm{CD} 27^{+} \mathrm{CD} 45 \mathrm{RA}$ population (green cells), and effector $\mathrm{CD} 8^{+} \mathrm{T}$ cells were defined as the $\mathrm{CD} 8^{+} \mathrm{CD} 27 \mathrm{CD}^{-} \mathrm{R} \mathrm{RA}^{+}$population (red cells). Naïve $\mathrm{CD} 8^{+} \mathrm{T}$ cells were defined as $\mathrm{CD}^{+} \mathrm{CD} 27^{+} \mathrm{CD} 45 \mathrm{RA}^{+}$(blue cells). Peripheral blood mononuclear cells were analyzed by flow cytometric analysis using IOTest Beta Mark TCR Vb repertoire kit (Beckman Coulter) according to the manufacturer's instruction.

stopping TKI treatment are still unclear. In contrast, patients who obtained TFR after interferon alpha treatment showed upregulation of cellular immunity, including CD8 ${ }^{+} \mathrm{T}$ cells and NK cells (13-15). Furthermore, allogeneic donor lymphocyte infusion has been reported to be effective in relapsed CML patients (8). These data suggest that upregulation of cellular immunity is critical to eliminate CML stem cells and obtain TFR. All three TKIs (imatinib, dasatinib, and nilotinib) can inhibit not only BCR-ABL but also other tyrosine kinases, such as KIT, PDGFR, and SRC (4). However, the increase in large granular lymphocytes (LGLs) has only been reported in patients treated with dasatinib (16). Activation of NK cells and CTLs also was observed in those patients $(9,10)$. By contrast, clonal expansion of TCR $V b$ genes in patients who receive multiple TKI therapies has been reported using polymerase chain reaction (PCR)-based clonality testing (44\% in dasatinib-treated patients, $46 \%$ in imatinib-treated patients, and $33 \%$ in nolitinib-treated patients) (17).

Cessation of dasatinib treatments induces a rapid decline in the LGL counts, almost to the baseline levels (18). Similarly, in Case 1, we observed an elevation of lymphocytes immediately after changing to dasatinib treatment, and a decrease in lymphocyte levels was observed soon after cessation of dasatinib treatment (Fig. 1A), while there was no obvious elevation of lymphocytes observed in Cases 2 and 3 (Fig. 1B and C). The immunological analyses of Case 1 showed not only maintenance of memory and effector CTL activation and NK cells, but also TCR clonality more than 2.4 years from cessation of dasatinib, despite the absence of lymphocyte elevation (Figs. 1A and 2, Table I). NK cells and CTLs were also analyzed in Cases 2 and 3 (Table I and Fig. 2); the percentages of NK cells and terminal effector CTLs were higher in Case 1 compared to Case 2 and 3, while there were no differences between effector memory $\mathrm{T}$ cells among the three cases (Table I). TCR $V b$ gene analysis revealed that there was marked elevation of $\mathrm{Vbl3.1}$ in memory $\mathrm{CD}^{+} \mathrm{T}$ cells in Case $1(65.1 \%)$, but no such elevation of $T C R V b$ genes was observed in the two control patients (Fig. 2). These data suggest that the maintenance of cellular immunity against CML protected the patient from CML relapse and provided a cure. Although LGLs were not observed in the patients treated with imatinib and nilotinib, TCR clonality was observed in approximately $45 \%$ of these patients by PCR-based TCR repertoire analyses (17). Both control patients could not retain long-term MR5 status, which may be related to the absence of significant clonality in the 
TCR repertoire of memory $\mathrm{CD}^{+} \mathrm{T}$ cells. These data suggest that the activation of CTLs against CML plays an important role in obtaining TFR in patients treated with TKIs. If this speculation is correct, testing the $T C R V b$ repertoire may be a useful tool to consider whether TKI treatment can be safely stopped under stringent treatment conditions.

In summary, we report a case of MR5 more than 2.4 years after cessation of dasatinib. Maintenance of memory and effector CTLs with TCR clonality as well as NK cells was observed in this case. These data suggest that clonal expansion of CTLs against CML cells may be a meaningful marker for cessation of TKIs.

\section{Acknowledgements}

The authors would like to thank Ms. Kana Okabe for her editorial work.

\section{References}

1. O'Brien SG, Guilhot F, Larson RA, Gathmann I, Baccarani M, Cervantes F, Cornelissen JJ, Fischer T, Hochhaus A, Hughes T, et al: Imatinib compared with interferon and low-dose cytarabine for newly diagnosed chronic-phase chronic myeloid leukemia. N Engl J Med 348: 994-1004, 2003.

2. Kantarjian H, Shah NP, Hochhaus A, Cortes J, Shah S, Ayala M, Moiraghi B, Shen Z, Mayer J, Pasquini R, et al: Dasatinib versus imatinib in newly diagnosed chronic-phase chronic myeloid leukemia. N Engl J Med 362: 2260-2270, 2010

3. Saglio G, Kim DW, Issaragrisil S, le Coutre P, Etienne G, Lobo C, Pasquini R, Clark RE, Hochhaus A, Hughes TP, et al: Nilotinib versus imatinib for newly diagnosed chronic myeloid leukemia. N Engl J Med 362: 2251-2259, 2010.

4. Hantschel O, Rix U and Superti-Furga G: Target spectrum of the BCR-ABL inhibitors imatinib, nilotinib and dasatinib. Leuk Lymphoma 49: 615-619, 2008.

5. Mahon FX, Réa D, Guilhot J, Guilhot F, Huguet F, Nicolini F, Legros L, Charbonnier A, Guerci A, Varet B, et al: Discontinuation of imatinib in patients with chronic myeloid leukaemia who have maintained complete molecular remission for at least 2 years: The prospective, multicentre Stop Imatinib (STIM) trial. Lancet Oncol 11: 1029-1035, 2010

6. Ross DM, Branford S, Seymour JF, Schwarer AP, Arthur C, Yeung DT, Dang P, Goyne JM, Slader C, Filshie RJ, et al: Safety and efficacy of imatinib cessation for CML patients with stable undetectable minimal residual disease: Results from the TWISTER study. Blood 122: 515-522, 2013.

7. Imagawa J, Tanaka H, Okada M, Nakamae H, Hino M, Murai K, Ishida Y, Kumagai T, Sato S, Ohashi K, et al: Discontinuation of dasatinib in patients with chronic myeloid leukaemia who have maintained deep molecular response for longer than 1 year (DADI trial): A multicentre phase 2 trial. Lancet Haematol 2 : e528-e535, 2015.
8. Kolb HJ, Schattenberg A, Goldman JM, Hertenstein B, Jacobsen N, Arcese W, Ljungman P, Ferrant A, Verdonck L, Niederwieser D, et al: Graft-versus-leukemia effect of donor lymphocyte transfusions in marrow grafted patients. Blood 86: 2041-2050, 1995.

9. Mustjoki S, Ekblom M, Arstila TP, Dybedal I, Epling-Burnette PK, Guilhot F, Hjorth-Hansen H, Höglund M, Kovanen P, Laurinolli T, et al: Clonal expansion of T/NK-cells during tyrosine kinase inhibitor dasatinib therapy. Leukemia 23: 1398-1405, 2009.

10. Kim DH, Kamel-Reid S, Chang H, Sutherland R, Jung CW Kim HJ, Lee JJ and Lipton JH: Natural killer or natural killer/T cell lineage large granular lymphocytosis associated with dasatinib therapy for Philadelphia chromosome positive leukemia. Haematologica 94: 135-139, 2009.

11. White HE, Matejtschuk P, Rigsby P, Gabert J, Lin F, Lynn Wang Y, Branford S,Müller MC, Beaufils N,Beillard E, etal: Establishment of the first World Health Organization International Genetic Reference Panel for quantitation of BCR-ABL mRNA. Blood 116: e111-e117, 2010.

12. Sasaki K, Strom SS, O'Brien S, Jabbour E, Ravandi F, Konopleva M, Borthakur G, Pemmaraju N, Daver N, Jain P, et al: Relative survival in patients with chronic-phase chronic myeloid leukaemia in the tyrosine-kinase inhibitor era: Analysis of patient data from six prospective clinical trials. Lancet Haematol 2: e186-e193, 2015.

13. Rohon P, Porkka K and Mustjoki S: Immunoprofiling of patients with chronic myeloid leukemia at diagnosis and during tyrosine kinase inhibitor therapy. Eur J Haematol 85: 387-398, 2010.

14. Kreutzman A, Rohon P, Faber E, Indrak K, Juvonen V, Kairisto V, Voglová J, Sinisalo M, Flochová E, Vakkila J, et al: Chronic myeloid leukemia patients in prolonged remission following interferon- $\alpha$ monotherapy have distinct cytokine and oligoclonal lymphocyte profile. PLoS One 6: e23022, 2011.

15. de Castro FA, Palma PV, Morais FR, Simões BP, Carvalho PV, Ismael SJ, Lima CP and Voltarelli JC: Immunological effects of interferon-alpha on chronic myelogenous leukemia. Leuk Lymphoma 44: 2061-2067, 2003.

16. Schiffer CA, Cortes JE, Hochhaus A, Saglio G, le Coutre P, Porkka K, Mustjoki S, Mohamed H and Shah NP: Lymphocytosis after treatment with dasatinib in chronic myeloid leukemia: Effects on response and toxicity. Cancer 122: 1398-1407, 2016.

17. Powers JJ, Dubovsky JA, Epling-Burnette PK, Moscinski L, Zhang L, Mustjoki S, Sotomayor EM and Pinilla-Ibarz JA: A molecular and functional analysis of large granular lymphocyte expansions in patients with chronic myelogenous leukemia treated with tyrosine kinase inhibitors. Leuk Lymphoma 52: 668-679, 2011.

18. Kreutzman A, Juvonen V, Kairisto V, Ekblom M, Stenke L, Seggewiss R, Porkka K and Mustjoki S: Mono/oligoclonal T and NK cells are common in chronic myeloid leukemia patients at diagnosis and expand during dasatinib therapy. Blood 116: 772-782, 2010.

This work is licensed under a Creative Commons Attribution-NonCommercial-NoDerivatives 4.0 International (CC BY-NC-ND 4.0) License. 